\title{
Per-vaginal handling of Schistosomus reflexus as a cause of dystocia in a Goat
}

\author{
D. N. Suthar*, V. K. Sharma, V. S. Dabas and D. B. Bhoi \\ Clinical Complex Deesa, College of Veterinary Science and Animal Husbandry \\ S. D. Agricultural University, Deesa-385535 (Gujarat), India. \\ * Corresponding author email : drdipaksuthar@yahoo.co.in \\ Published Online : 30-04-2011
}

\section{Introduction}

Schistosomus reflexus is a rare fatal congenital disorder primarily observed in ruminants. However, dystocia due to this monster is comparatively rare in goat than in cattle and buffalo (Roberts, 1971). Fetotomy or caesarean section is mandatory for delivery of a fully grown schistosomus reflexus monster while, per-vaginal expulsion without any obstetrical assistance is noticed in small sized monster fetuses (Kalita et al., 2004). A successful per-vaginal management of dystocia due to schistosomus reflexus monster in a doe is placed on record.

\section{Case history and clinical observations}

A four years full term pregnant non-descript doe in her third parity was presented with the history of labour since 12 hours. Clinically, the fetal abdominal viscera were protruding out of vulva (Fig.1). The rectal temperature was $102.9^{\circ} \mathrm{F}$. Per-vaginally, the cervix was sufficiently dilated that facilitated the palpation of a normal sized dead schistosomus reflexus fetus in the right horn in anterior presentation and dorso-sacral position.

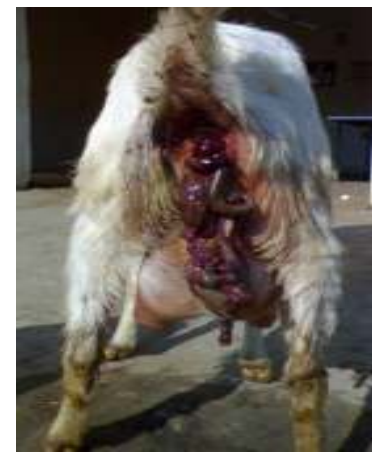

Figure-1. Fetal abdominal viscera protruding out of vulva.

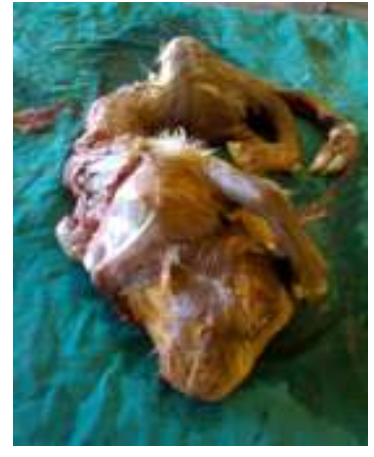

Figure-2. Schistosomus reflexus fetus delivered pervaginum.

\section{Treatment and Discussion}

Since the genital tract was sufficiently relaxed and lubricated, the foetus was delivered per-vaginum by mild traction with hand on the forelimbs and head along with simultaneous adjustment of the other foetal parts. Subsequently, the after births were pulled out and two boluses of Furea were placed intra-uterine. There was absence of any apparent injury to the genital tract of the dam. Parentally, the animal was treated with antibiotic, analgesic and antihistaminic in prescribed doses.

Morphologically, there were ankylosed foetal limbs, angulated lumbar region and abnormal ' $\mathrm{S}$ ' shaped curve of the thoracic region (Fig.2). The diaphragm was intact and the lungs were atrophied. The congested abdominal viscera viz. stomach, intestines liver etc. were protruded out of the abdominal cavity.

Foetal monster with herniation of abdominal viscera and skeletal defects (Dennis and Mayer, 1965) is referred to as Schistosomus reflexus. The condition is common in cattle and buffaloes (Padma Rao et al., 1993 and Srivastava et al., 1998) and can be corrected either by fetotomy or caesarean section. Although, the Schistosomus reflexus monster is rare in goat the similar cases in co-twins were reported by Kalita et al (2004) and Tripathi et al (2008).

\section{References}

1. Dennis, S. M. and Mayer, E. P. (1965). Schistosomus reflexus in a sheep. Vet. Rec. 77: 1386.

2. Kalita, D., Bhuyan, D., Mukit, A. and Islam, S. (2004). Dystocia due to Schistomus reflexus in a goat. Indian J. Anim. Reprod. 25 (1): 76-77.

3. Padma Rao, V., Ramchandraiah, K., Mohan Reddy, A. R., Venkata Subbiah, D. and Chandrasekhar, B. (1993). Schistosomus reflexus in a monocephalus tripus dibrachius calf. Indian Vet. J. 70: 1083.

4. Roberts, S. J. (1971). Veterinary obstetrics and genital diseases, $2^{\text {nd }}$ Edn. C.B.S. Publisherand distributors, Delhi. p.70-73. 
Per-vaginal handling of Schistosomus reflexus as a cause of dystocia in a Goat

5. Srivastava, K. K., Sharma, A. K., Ahlawat, S. P. S. and Maithy, S. K.(1998). Schistosomus reflexus with perosomus elumbis in Holstein Friesian cow. Indian J. Anim. Reprod. 19 (1): 75.
6. Tripathi, S. D., Chaudhary, K. S., Raut, S. S., Chauhan, A. R., Rohi, R., Katkar, S. M., Patil, D. J. (2008). A Case of Foetal Dystokia due to Schistosoma reflexus in a Goat. The Journal of Bombay Veterinary College. Vol: 16(1). 